\title{
Maternal uniparental disomy of chromosome 13 in a phenotypically normal child
}

\author{
Howard Slater, Janet H Shaw, Gary Dawson, Agnes Bankier, Susan M Forrest
}

\begin{abstract}
A case of maternal uniparental disomy of chromosome 13 is described. The subject is a phenotypically normal male who inherited a $t(13 ; 13)(p 11.2 ; p 11.2)$ from his mother who is a carrier of this translocation. The mother was ascertained through a history of recurrent abortion and is phenotypically normal. The translocation in both subjects was studied by cytogenetic and DNA analysis and appears to be a true dicentric isochromosome. These findings show that maternal uniparental disomy of chromosome 13 has had no pathological consequences and suggests that there is no imprinting of genes on maternally derived chromosome 13.
\end{abstract}

\section{(f Med Genet 1994;31:644-646)}

The high observed rates of nullisomy and disomy for many chromosomes in human gametes led Engel ${ }^{1}$ in 1980 to propose the concept of uniparental disomy (UPD). UPD describes the inheritance within a somatic cell's chromosome complement of a pair of homologous chromosomes derived from only one parent rather than the normal derivation of one chromosome from each parent.

There have been several reports of UPD in association with de novo and familial isochromosomes. Some of these have been associated with phenotypic abnormality. Maternal isodisomy for chromosome 14 was described in a female ascertained through a history of recurrent abortion who had a $\operatorname{rob}(14 ; 14)$. The patient was also homozygous for a recessive gene causing rod monochromacy, a defect in colour vision. ${ }^{2}$ Paternal and maternal uniparental disomy for chromosome 15 have been shown in association with Angelman and Prader-Willi syndromes respectively. Both patients had an isochromosome 15, the disorders being a consequence of imprinting. ${ }^{34}$ Two independent cases of probable UPD for chromosome 22 have been described where a $t(22 q 22 q)$ has been inherited from a carrier mother. ${ }^{56}$ Neither case was investigated with molecular analysis to distinguish between hetero- and isodisomy. One de novo case with a $\mathrm{t}(22 \mathrm{q} 22 \mathrm{q})$ has been shown to be probable maternal isodisomy. ${ }^{7}$ None of these cases was associated with phenotypic abnormality. There have been two de novo cases of $t(21 q 21 q)$ in phenotypically normal subjects investigated for UPD, one of maternal origin ${ }^{8}$ and the other showing paternal uniparental isodisomy. ${ }^{49}$

The questions of whether UPD for chromosome 13 exists and whether it has phenotypic consequences have not been previously answered and are addressed in this paper, which describes a molecular analysis of a phenotypically normal male who has a maternally inherited $\mathrm{t}(13 \mathrm{q} 13 \mathrm{q})$.

\section{Case report}

The proband was a 5 year old male child who appeared to have a completely normal developmental history. His weight, and head circumference were at the 75 th, 50th, and 50th centiles respectively; he had no dysmorphic features and was healthy. He was ascertained through his 37 year old mother who was referred for chromosome analysis with a history of five first trimester spontaneous abortions. She too was of normal intelligence, normal stature, and without dysmorphism.

\section{CYTOGENETIC STUDIES}

The mother's GTL banded karyotype contained a Robertsonian translocation involving the long arms and proximal regions of the short arms of two chromosomes 13; the distal acentric regions of short arm were lost. The karyotype is described as $45, \mathrm{XX},-13,-13,+\mathrm{t}(13 ; 13)$ (p11.2; p11.2); it is not known if this was a de novo rearrangement as, although the child's grandmother had a normal karyotype, the grandfather was not available for study. Subsequent chromosome analysis of her son's karyotype showed the same $t(13 ; 13)$, that is, $45, \mathrm{XY},-13,-13,+\mathrm{t}(13 ; 13)(\mathrm{p} 11.2 ; \mathrm{p} 11.2)$; mosaicism was not detected. The Robertsonian translocation in both persons was further investigated by fluorescence in situ hybridisation ${ }^{10}$ using the probe alpha $R 1$, which is specific for the centromeres of chromosomes 13 and $21,{ }^{11}$ and also by chromosome painting using a 13 specific paint (Cambio). The abnormal chromosome was shown to be dicentric in both cases and consisted entirely of chromatin from chromosome 13 (data not shown).

\section{MOLECULAR STUDIES}

In order to confirm that the child had inherited his mother's $t(13 ; 13)$, the inheritance of chromosome 13 specific polymorphic DNA markers was investigated. Three polymorphic 
AC repeat polymorphisms were selected which are distributed along the length of the long arm of chromosome $13^{12}$; these were D13\$166, D13S173, and D13S175. PCR reactions were performed by standard methods ${ }^{13}$ using pairs of oligonucleotide primers which flank each of the AC repeat sequences and genomic DNA (100 ng per reaction) isolated from blood samples taken from the proband and both his parents. The primer sequences were obtained from the Genome Database (GDB), Johns Hopkins, Baltimore. Annealing temperatures of $61^{\circ} \mathrm{C}$ with D13S175 and $66^{\circ} \mathrm{C}$ with D13S166 and D13S173 were used. $\alpha-\left[{ }^{32} \mathrm{P}\right] \mathrm{CTP}$ was included in the reaction mixture and the PCR products separated on $8 \%$ denaturing polyacrylamide gels.

The child's mother was found to be homozygous for the three loci DS13S166, DS13S173, and DS13S175 (fig 1). For each of these three loci, the father had different alleles from the mother. The child's DNA contained exactly the same homozygous alleles as his mother and no paternal contribution was evident.

Inheritance of a microsatellite marker on chromosome 5 (JK53,D5S112) was consistent with paternity in this family.

\section{Discussion}

Since Engel originally postulated the existence of UPD in $1980,{ }^{1}$ several examples have been reported involving all or part of chromosomes $6,7,11,14,15,16,21,22$, and the XY pair. ${ }^{14}$

These investigations are of value firstly for determining which chromosomes contain imprinted genes and secondly for showing the chromosomal location of pathological, recessive mutations rendered homozygous by isodisomy. As an example of the former, the Prader-Willi syndrome is now frequently observed in diagnostic molecular genetics as the consequence of maternal uniparental disomy of chromosome 15. An example of the detection of recessive mutations is the linkage of autosomal recessive rod monochromacy to chromosome $14 .^{2}$
Studies in the mous $\mathrm{e}^{15}$ have shown that UPD for some chromosomes is not associated with phenotypic abnormality and similar findings have been reported for human chromosomes $21^{9}$ and $22 .{ }^{7}$ The mouse studies have also shown that UPD for other chromosomes is lethal for the developing conceptus. It has been suggested that maternal uniparental disomy of human chromosome 16 can similarly be a cause of embryonic death or intrauterine growth retardation although it is difficult to discount this being a result of residual trisomic cells. ${ }^{16}$

UPD for chromosome 14 has been reported in three cases $^{17-19}$ involving Robertsonian $(13 ; 14)$ translocations. Because of the relatively high frequency of this translocation in the general population, the absence of reported UPD for chromosome 13 could have been explained by failure of ascertainment owing to either lack of associated phenotypic abnormality or fetal incompatibility. Two human loci on chromosome 13 map to chromosome 14 in the mouse suggesting homology between these chromosomes. ${ }^{20}$ Chromosome 14 in the mouse has been shown not to be subject to imprinting. ${ }^{15}$

This study shows UPD for chromosome 13. The molecular genetic analysis provides strong evidence that the $t(13 ; 13)$ translocation in mother and child are identical translocations. Furthermore, the translocation appears to have produced a true isochromosome since all the polymorphic AC repeat alleles examined were homozygous despite all being highly $(>75 \%)$ polymorphic. ${ }^{12}$ Such a chromosome could have been formed by a translocation involving the breakpoints p11.2 in the short arms of identical chromosome 13 chromatids before anaphase in meiosis II thus producing a disomic gamete. The phenotypically normal mother probably also has UPD for chromosome 13 but in her case we were unable to determine its parental origin.

Two mechanisms leading to UPD in this case seem possible. ${ }^{14} \mathrm{~A}$ disomic ovum could have been fertilised by a nullisomic sperm resulting in a diploid zygote containing 45 chromosomes.

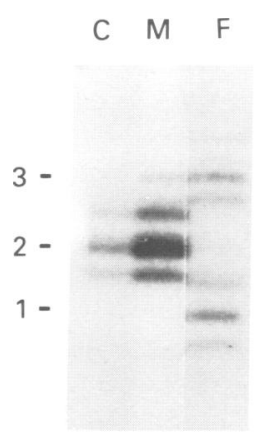

D13S175
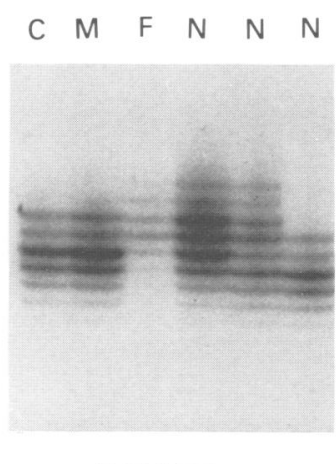

D13S173
C $\mathrm{M} F \mathrm{~N} N \mathrm{~N}$

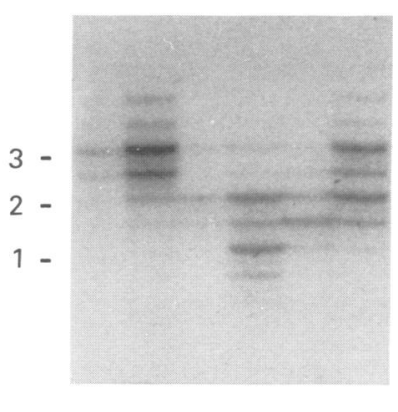

$13 S 166$

Allele segregation in the proband (C), mother $(M)$, and father $(F)$ of three $C A$ repeat polymorphisms, D13S175, $D 13 S 173$, and D13S166, which are located on the long arm of chromosome 13. Normal controls ( $N)$ were included to assist in allele definition. For D13S175, alleles were $C(2,2) ; M(2,2) ; F(3,1) ; D 13 S 173, C(2,2) ; M(2,2) ; F(4,3)$; D13S166, C (3,3);M(3,3); F(2,2). 
Alternatively, the conceptus could have been trisomic for chromosome 13, as a result of an ovum with the isochromosome having been fertilised by a normal sperm. Subsequent postzygotic embryo "rescue" through loss of the paternal chromosome 13 could then have occurred. Although no evidence for mosaicism was found either in the cytogenetic or molecular analyses, this mechanism cannot be discounted. As only a small proportion of blastomere cells are destined to form the embryo proper, ${ }^{21}$ mosaicism can be confined to the placenta if "rescue" takes place before formation of the embryonic inner cell mass.

In conclusion, this study shows for the first time that maternal UPD for chromosome 13 is not accompanied by phenotypic abnormality. Furthermore, our results indicate that there is no evidence for maternal imprinting on the long arm of chromosome 13 .

1 Engel E. A new genetic concept: uniparental disomy and its potential effect. Am $\mathcal{f}$ Genet 1980;6:137-43.

2 Pentao L, Lewis RA, Ledbetter DH, Patel PI, Lupski JR. Maternal uniparental isodisomy for chromosome 14: association with autosomal recessive rod monochromacy. $A m \mathcal{\jmath}$ Hum Genet 1992;50:690-9.

3 Freeman SB, May KM, Pettay D, Fernhoff PM, Hassold TJ Paternal uniparental disomy in a child with a balanced Paternal uniparental disomy in a child with a balanced 15;15 translocation and Angelman syndrome. Am f Hum

4 Robinson WP, Bernasconi F, Basaran S, et al. A somatic origin of homologous Robertsonian translocations and isochromosomes. Am f Hum Genet 1994;54:290-302.

5 Palmer CG, Schwartz S, Hodes MM. Transmission of a balanced homologous $t(22 q ; 22 q)$ translocation from mother to normal daughter. Clin Genet 1980;17;418-22.

6 Kirkels VGHJ, Hustinx TWJ, Scheres JMJC. Habitua abortion and translocation $(22 \mathrm{q} ; 22 \mathrm{q})$ : unexpected trans- location from a mother to her phenotypically normal daughter. Clin Genet 1980;18:456-61.

7 Schinzel AA, Basaran S, Bernasconi F, Karaman B, Yuksel Apak M, Robinson WP. Maternal uniparental disomy 22 has no impact on the phenotype. Am $\mathcal{f}$ Hum Gene 1994;54:21-4.

8 Creau-Goldberg N, Gegonne A, Delabar J, et al. Maternal origin of a de novo balanced $\mathrm{t}(21 \mathrm{q} 21 \mathrm{q})$ identified by etspolymorphism. Hum Genet 1987;76:396-8.

9 Blouin JL, Avramopoulos D, Pangolos C, Antonarakis SE Normal phenotype with paternal uniparental isodisomy fo chromosome 21. Am f Hum Genet 1993;53:1074-8.

10 Voullaire LE, Slater HR, Petrovic V, Choo KHA. A functional marker centromere with no detectable alpha-satellite, satellite III, or CENP-B protein: activation of a latent centromere? Am f Hum Genet 1993;52:1153-63.

11 Jorgensen AL, Bostock CJ, Bak AL. Homologous subfamilies of human alphoid repetitive DNA on different nucleolus organising chromosomes. Proc Natl Acad $S c i$ nucleolus organising

12 Weissenbach J, Gyapay G, Dib C, et al. A second generation linkage map of the human genome. Nature 1992;359:794 801

13 Saiki RK, Gelfand DH, Stoffel S, et al. Primer-directed enzymatic amplification of DNA with a thermostable DNA polymerase. Science 1980;239:487-91.

14 Engel E. Uniparental disomy revisited: the first twelve years. Am $\mathcal{F}$ Med Genet 1993;46:670-4.

15 Cattanach BM, Kirk M. Differential activity of maternall and paternally derived chromosome regions in mice. $\mathrm{Na}$ ture 1985;315:496-8. 16 Kalousek DK, Langois S, Barret I, et al. Uniparental disomy 1993;52:8-16.

17 Temple IK, Cockwell A, Hassold T, Pettay D, Jacobs P. Maternal uniparental disomy for chromosome 14. F Med Genet 1991;28:511-14.

18 Wang JCC, Passage MB, Yen PH, Shapiro LJ, Mohandas TK. Uniparental heterodisomy for chromosome 14 in a phenotypically abnormal familial balanced 13/14 Robertphenotypically abnormal familial balanced $13 / 14$ Robertsonian translocati

19 Antonarakis SE, Blouin JL, Maher J, Avramopoulos GT, Talbot Jr CC. Maternal uniparental disomy for human chromosome 14, due to loss of a chromosome 14 from somatic cells with $\mathrm{t}(13 ; 14)$ trisomy 14. Am $\mathcal{F}$ Hum Gene 1993;52:1145-52.

20 Searle AG, Peters J, Lyon MF, et al. Chromosome maps of man and mouse Ann Hum Genet 1989;53:89-140.

21 Kalousek DK. Confined placental mosaicism. Pediatr Patho 1990;10:69-77. 